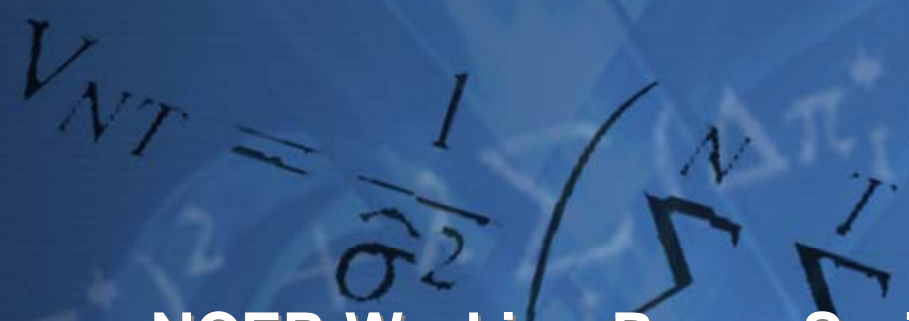

NCER Working Paper Seriés

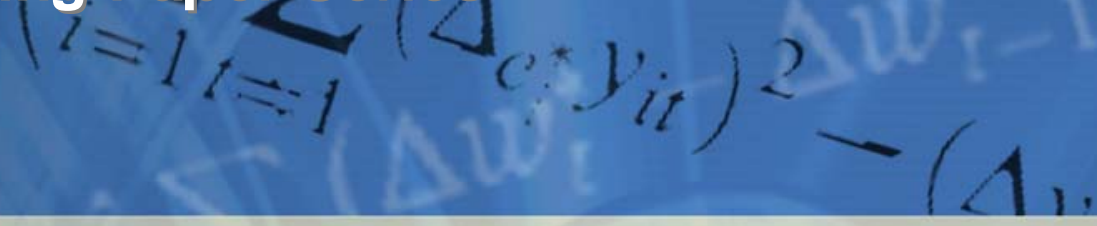

Cojumping: Evidence from the US Treasury Bond and Futures Markets

Mardi Dungey

Lyudmyla Hvozdyk

Working Paper \#56 July 2010 


\title{
Cojumping: Evidence from the US Treasury Bond and Futures Markets*
}

\author{
Mardi Dungey*+ $^{*+}$ and Lyudmyla Hvozdyk ${ }^{+}$ \\ * University of Tasmania \\ + CFAP, University of Cambridge
}

14 July 2010

\begin{abstract}
The basis between spot and future prices will be affected by jump behavior in each asset price, challenging intraday hedging strategies. Using a formal cojumping test this paper considers the cojumping behavior of spot and futures prices in high frequency US Treasury data. Cojumping occurs most frequently at shorter maturities and higher sampling frequencies. We find that the presence of an anticipated macroeconomic news announcement, and particularly non-farm payrolls, increases the probability of observing cojumps. However, a negative surprise in non-farm payrolls, also increases the probability of the cojumping tests being unable to determine whether jumps in spots and futures occur contemporaneously, or alternatively that one market follows the other. On these occasions the market does not clearly signal its short term pricing behavior.
\end{abstract}

JEL Categories: C1, C32, G14

Keywords: US Treasury markets, high frequency data, cojump test

*We are grateful to Ross Adams for managing the database. We would like to thank Brett Inder, Petko Kalev, Michael McKenzie and Hashem Pesaran for constructive comments on this paper as well as participants at the Cambridge Finance Workshop, seminars at the Judge Business School, Monash University and the University of Tasmania, conferences at Warwick Business School and Princeton University for helpful discussions. Author contacts: Dungey, mardi.dungey@utas.edu.au, Hvozdyk, l.hvozdyk@cerf.cam.ac.uk. 


\section{Introduction}

The joint behavior of spot and future prices for a single asset is an area of considerable interest to financial markets. Research into hedging using spot and futures includes papers by Stein (1961), those surveyed by Lien and Tse (2002) and recently Lee (2010). The literature on price discovery in these markets generally favours information flowing from futures markets to spot, see for example, Rosenberg and Traub (2006), Mizrach and Neely (2008) and Chen and Gau (2010). Information arrival is often associated with price discontinuities, known as jumps, and evidence from high frequency data now strongly suggests that these may occur at the same time across a number of different asset prices, see particularly Andersen et al. (2007a), Dungey et al. (2009a) and Lahaye et al. (2010). An intraday portfolio management strategy involves recognizing and responding to such jumps. In particular, a speculative positioning on the basis between spot and futures prices requires a view of whether jumps in the two prices are matched in time, or indeed matched at all on an intraday frequency.

This paper examines the joint behavior of the spot and futures markets for US Treasury bonds using a formal joint test of cojumping recently developed by Jacod and Todorov (2009). The spot and futures prices for US Treasuries are already known to jump individually; see for example Jiang and Yan (2009), Dungey et al. (2009a), Lahaye et al. (2010), Andersen et al. (2007a). ${ }^{1}$ However, to our knowledge, the question of cojumping across spot and futures markets for the same assets is previously unstudied. In addition to considering the evidence for spot and futures cojumping, we additionally consider the jumping behavior across the term structure for each of the assets, extending the univariate test results in Dungey et al. (2009a). Contemporaneous jumps across the term structure are consistent with liquidity preference theory, while more idiosyncratic jumps support segmented markets.

The Jacod and Todorov procedure comprises two tests, conducted on individual price series in which jumps are already known to occur. One test has the null hypothesis of contemporaneous jumps across multiple asset prices (cojumping), while the other has the null hypothesis of disjoint jumps (or no cojumping). The tests build on the standard assumptions of a continuous price process with discrete interruptions (the jumps), where the multipower quadratic variation of the returns for the chosen time period, usually one day, can be consistently estimated by realized variance. Jacod and Todorov recognize that under the null of common jumps the ratio of realized variances at different sampling frequencies will be the same, so that the hypothesis can be rejected when this is not the case. Alternatively, in the case of a null of disjoint jumps, the ratio of the realized variance to the square root of product of the quadratic returns of the individual asset

\footnotetext{
${ }^{1}$ The particular univariate testing frameworks include Barndorff-Nielsen and Shephard (2004, 2006), Aït-Sahalia and Jacod (2009) and Lee and Mykland (2008).
} 
returns tends to zero (that is there is no evidence that the movements occur together).

High frequency US Treasury spot prices are drawn from eSpeed, one of the two dominant ECNs trading these assets in the post-2000 era. Earlier work, such as Mizrach and Neely (2008) use data from the now superseded GovPX platform, which operated a voice over protocol. Corresponding data for the futures sample are obtained from the Chicago Mercantile Exchange, suitably transformed for nearest contract.

Working with 2, 5, 10 and 30 year maturity contracts we find evidence of cojumping between spot and futures prices, and that cojumping often occurs in response to the surprise component of scheduled US macroeconomic news announcements. There are more jumps in the futures contracts than the spot contracts, however, there are also periods when the spot market jumps but the futures market does not. The results also clearly show that the evidence for cojumping increases monotonically with maturity (that is longer dated securities are more likely to cojump than short-dated) and also increases with sampling frequency.

Given that the cojumping test proposed by Jacod and Todorov (2009) have two components, we find some periods where these tests are in conflict, so that one test suggests a cojump in the two assets and the other rejects its presence. The extent of this is far greater than anticipated. We therefore confirm the sample properties of the tests via an extension of the Monte Carlo study of Jacod and Todorov (2009) which takes into account the highly correlated nature of spot and futures prices. As we find that the contradictory test results are not an artefact of the test behavior, we consider the influence of news. Simple tabulations suggest that the conflicting results in the spot and futures pairs occur predominantly in the presence of negative surprises for US non-farm payrolls data. Formal regression analysis confirms that macroeconomic news arrival influences not only the probability of a jump, a result found in previous papers, but also the probability of observing an contradictory result. In these contradictory instances the hedging signals are unclear, as the tests are unable to reveal whether the basis has changed due to a jump in one asset, implying a potential arbitrage opportunity in the other asset, or due to different sized contemporaneous jumps in both assets. This likely reflects uncertainty around the news announcement, leading to moves which are inconsistent with the underlying continuous data generating process as the market attempts to establish a new equilibrium. For an intraday speculator or portfolio manager, it is potentially important to recognize that these periods of confusion, and hence opportunity, occur primarily in association with news releases, and particularly in response to the release of negative surprises in non-farm payrolls data.

The paper is organized as follows. Section 2 presents formal jump test methodologies. The data are described in Section 3 and the results of the cojumping test applied to maturity pairs of futures and spot data are discussed in Section 4. In Section 5 the small sample properties of the jumps test are examined in a Monte Carlo with correlated prices. 
The relationships between cojumping and news, and contradictory test result occurrences and news are analyzed in Section 6. Finally, Section 7 concludes.

\section{Methodology}

\subsection{Univariate Jump Test}

The jump days for each series are determined using the univariate jumps test of BarndorffNielsen and Shephard (2006), henceforth BNS, which is a specific case of the more general proposal of Aït-Sahalia and Jacod $(2009)^{2}$. Assume that an individual asset price, $x_{i t}$, is an Itô semi-martingale process

$$
x_{i t}=\int_{0}^{t} b_{s} d s+\int_{0}^{t} \sigma_{s} d W_{s}+\sum_{j=1}^{N} c_{j t},
$$

where $x_{t}$ represents the price of the asset at time $t$, and the right hand side terms represent a continuous, locally bounded variation process, $b_{t}$, a strictly positive stochastic volatility process, $\sigma_{t}, W_{t}$ is Brownian motion and the final term is a jump process where $c_{j t}$ assumes a Poisson arrivals process with $N$ possible jump occurrences. Returns for $\delta$ intervals are given by $r_{t+j \delta, \delta}=x_{t+i \delta}-x_{t+(j-1) \delta}$. The realized variance for each period $t$ (one day in the application here) is sum of squared $\delta$ period returns which converges as $\delta \rightarrow 0$ to the true quadratic variation and squared jumps,

$$
R V_{t+1}(\delta)=\sum_{i=1}^{1 / \delta} r_{t+i \delta, \delta}^{2} \rightarrow \int_{0}^{t} \sigma_{s}^{2} d s+\sum_{0<s \leq t} c_{s}^{2},
$$

while the product of absolute adjacent $\delta$ period returns, or bipower variation converges to quadratic variation,

$$
B V_{t+1}(\delta)=\mu_{1}^{-2} \sum_{i=2}^{1 / \delta}\left|r_{t+i \delta, \delta}\right|\left|r_{t+(i-1) \delta, \delta}\right| \rightarrow \int_{0}^{t} \sigma_{s}^{2} d s
$$

where $\mu_{1}=\sqrt{2 / \pi}$ is a normalizing coefficient.

The BNS test recognizes that as $\delta \rightarrow 0$ the difference between realized volatility and bipower variation converges to a jumps only component

$$
R V_{t+1}(\delta)-B V_{t+1}(\delta) \rightarrow \sum_{0<s \leq t} c_{s}^{2}
$$

\footnotetext{
${ }^{2}$ We also applied Aït-Sahalia and Jacod (2009) univariate jump test but found that it has poor small sample properties for our case and is not reported here. See also footnote 4 on the small sample properties.
} 
which is modified to account for potential negative observations and serial correlation following Huang and Tauchen (2005) as

$$
J S_{t+1}(\delta)=\left(R V_{t+1}(\delta)-B V_{t+1}(\delta)\right) /\left(\left(\mu_{1}^{-4}+2 \mu_{1}^{-2}-5\right) \delta \int_{t}^{t+1} \sigma^{4}(s) d s\right)^{-1 / 2} \sim N(0,1) .
$$

\subsection{Bivariate Jump Test}

While Barndorff-Nielsen and Shephard (2004) extend the concepts of bipower variation and realized variance to multivariate equivalents, the corresponding multivariate test is currently incomplete. An alternative is the extension to the bivariate case presented in Jacod and Todorov (2009). The assumed structure for the pricing process of the financial market assets is now expressed for a vector, $x_{t}$, where for convenience $x_{t}$ represents the bivariate case of the current paper. Formally,

$$
\begin{aligned}
x_{t}= & x_{0}+\int_{0}^{t} b_{s} d s+\int_{0}^{t} \sigma_{s} d W_{s}+\int_{0}^{t} \int \kappa^{\prime} \circ \theta(s, x)(\mu-v)(d s, d x) \\
& +\int_{0}^{t} \int \kappa^{\prime} \circ \theta(s, x) \mu(d s, d x),
\end{aligned}
$$

where $b_{t}$ is the deterministic drift coefficient, $W_{t}$ a Wiener process, and $\mu$ a Poisson random measure (the jumps). The intensity of the jumps is $v$ with a truncation function $\kappa(x)=x$ on a neighborhood of 0 . Both $b_{t}$ and $\theta$ are 2-dimensional processes in the 2 asset case and the $2 \times 2$ variance-covariance matrix of the returns, $\sigma_{t}$, is non-trivially assumed to evolve with the same Itô semimartingale form as (4), that is there are drift and jump terms in the evolution of the volatility.

There are three complementary sets to which the observed price paths may belong: $\Omega_{t}^{J}$, when the series cojump (that is both series jump contemporaneously), $\Omega_{t}^{D}$ when the individual series jump but do not cojump, known as disjoint jumps and $\Omega_{t}^{C}$, when at least one of the series is continuous, that is displays no jumps. Jacod and Todorov eliminate $\Omega_{t}^{C}$ from consideration by pretesting individual series for the presence of jumps using univariate jump test series - so that interest is focussed purely on the jumping series.

The formal tests of jumps across multiple series are based on the use of the power variation estimators, where $r_{t+j \delta, \delta}$ is the vector of return series:

$$
V(f, \delta)_{t}=\sum_{j=1}^{[1 / \delta]} f\left(r_{t+j \delta, \delta}\right) \text { and } V(g, \delta)_{t}=\sum_{j=1}^{[1 / \delta]} g\left(r_{t+j \delta, \delta}\right) .
$$

The first test uses a null of common jumps, and compares the power variation of the returns series at two different sampling frequencies (scales), $\delta$ and $k \delta$ where $k$ is a positive integer. The test statistic, $\Phi_{t}^{(J)}$ converges to one under the null of common jumps:

$$
\Phi_{t}^{(J)}=\frac{V(f, k \delta)_{t}}{V(f, \delta)_{t}} \stackrel{P}{\longrightarrow} 1
$$


where

$$
V(f, \delta)_{t} \stackrel{P}{\longrightarrow} \hat{B}_{t}=\sum_{s \leq t}\left(r_{1, s}\right)^{2}\left(r_{2, s}\right)^{2} .
$$

The second test has a null of disjoint jumps (or equivalently there are no common jumps) and the test statistic, $\Phi_{t}^{(D)}$, has the form

$$
\Phi_{t}^{(D)}=\frac{V(f, \delta)_{t}}{\sqrt{V\left(g_{1}, \delta\right)_{t} V\left(g_{2}, \delta\right)_{t}}} \stackrel{P}{\longrightarrow} 0
$$

where

$$
V\left(g_{i}, \delta\right)_{t} \stackrel{P}{\longrightarrow} \hat{B}_{i, t}^{\prime}=\sum_{s \leq t}\left(r_{i, s}\right)^{4}
$$

The tests have critical regions based on $C_{t}^{(J)}=\left\{\left|\Phi_{t}^{(J)}-1\right| \geq c_{t}^{(J)}=z_{\alpha} \frac{\sqrt{\delta}}{V(f, \delta)_{t}}\right\}$ and $C_{t}^{(D)}=$ $\left\{\Phi_{t}^{(D)} \geq \frac{\delta\left(Z_{t}^{(D)}(\alpha)+\hat{A}_{t}\right)}{\sqrt{V\left(g_{1}, \delta\right)_{t} V\left(g_{2}, \delta\right)_{t}}}>0\right\}$ where $Z_{t}^{(D)}(\alpha)$ is the normalized order statistic based on the normalized truncated power variation and $\hat{A}_{t}$ is an alternative truncated power estimator (Jacod and Todorov, 2009).

\section{Data Description}

US Treasury markets are large in terms of turnover per trading day. Futures trade volume is greater than spot, but the turnover in the spot market itself is substantial; an average trade volume of $\$$ US524.7 billion per day was recorded in 2006 (see Spiegel, 2008). In this paper the data set for spot trade in US Treasury bonds is drawn from the CantorFitzgerald eSpeed trade file and comprises tick by tick transaction prices for the 2, 5, 10 and 30 year US Treasury bonds. The eSpeed platform is one of two dominant ECNs in this market, the other being ICAP's BrokerTec, and the characteristics of the trading volume on the two platforms are not significantly different (compare the data in Dungey et al., 2009a and Jiang et al., 2010). Futures contracts on the same maturity Treasury bonds are sourced from the Chicago Mercantile Exchange and are also tick by tick data for transactions on that platform. The common span of these data sets is from January 2, 2002 to December 31, 2006 with a trading day defined as the period from 7:30a.m. to 5:30p.m. New York time. Weekends and public holidays are excluded from the sample. The market is very liquid - for example only 4 percent of the 5 minute intervals contain no spot trade in the 5 year bond.

Discretized spot and futures data are constructed such that the last transaction in an interval indicates the price at the end of the interval. A number of different sampling frequencies have been applied in studies of jumps thus far. Lahaye et al. (2010) use 15 minutes, Huang and Tauchen (2005) and Andersen et al. (2007a) sample at 5 minute intervals, while Dungey et al. (2009a) produce results for a number of different frequencies. Unfortunately, the optimal sampling frequency tests proposed by Bandi and Russell 
(2006) give no guidance on the appropriate means of choosing sampling frequency for multiple series considered contemporaneously, particularly in the case of different trade intensities as in the current problem. Consequently, we consider three sampling frequencies, namely 1, 5 and 10 minute intervals.

Examples of the intraday returns and potential jump behavior of the data are given in Figure 1, which presents 5 minute returns in 5 year spot and futures data for two particular days where US non-farm payrolls data were released to the market. The Figure shows that there are clear disruptions in the price processes at the time of those announcements.

Descriptive statistics for the intraday returns data are presented in Table 1 . The largest average returns are obtained for the 30 year bonds $(0.0003 \%)$ at 10 minute intervals. As the sampling frequency increases, the average returns decrease, with the futures returns approaching 0 faster than the corresponding spot transactions. Futures returns tend to be more volatile than spot returns. For example, at 5 minute intervals, the standard deviation of the 5 year and 10 year maturity futures is almost 8 times the standard deviation of the spot return (0.024 versus 0.170 and 0.040 versus 0.276 ). The highest standard deviation is obtained for the 30 year securities with the volatility in the futures again higher than that in the spot returns.

\section{Empirical Tests}

\subsection{Univariate Test}

The appropriate sample period to search for jumps is taken to be one trading day. The filter for days where individual series jump is the BNS univariate jump test.

The application of the univariate jumps tests reveals a considerable number of days when both spot and futures contracts of the same maturity exhibit jumps. The results are summarized in Table 2, which gives the number of days on which a jump is detected and the corresponding rejection frequency for the null hypothesis of no univariate jumps for each series. The rejection frequencies of the null hypothesis of no univariate jumps are generally higher for futures contracts than for the corresponding maturity spot contracts (except for the 30 year futures at the 10 minute interval). It is also apparent that as sampling frequency increases the number of test rejections increases. This result is especially striking for the 1 minute sampling frequency where rejection rates are all over $85 \%$. An increased prevalence of microstructure noise in more frequently sampled data may be behind this result, although it is difficult to differentiate on statistical criteria between noise and information. The rejection rates for the null of no jumping in the futures contracts decrease monotonically as the maturity increases from the 2 year to 30 year. This also holds for spot contracts at 10 minute intervals but is mixed at higher 
frequencies.

When both spot and futures series in the maturity pair jump individually, this day is defined as a common jump day. (Note that a common jump day is a day on which jumps in both series occur, but not necessarily contemporaneously.) The number of these days is recorded in the penultimate column of Table 2, and the proportion of the total sample days this represents in the final column. The numbers vary depending on the sampling frequency: for the 30 year maturity pair the common days are 87 at the 10 minute sampling frequency and 1106 at the 1 minute frequency. Common jump days are taken as the sample for the cojumping tests.

\subsection{Bivariate Test: Bond and Futures Maturity Pairs}

The cojumping tests apply to days where both series exhibit jumps individually. We test for cojumping behavior across spot and futures contracts of the same maturity, and secondly on pairs of assets of differing maturity within the term structure of the spot or futures markets. Hence there are 4 maturity pairs in the spot and futures matched maturity sample: 2, 5, 10 and 30 year contracts, and 6 maturity pair combinations within each of the spot and futures datasets: 2 and 5, 2 and 10, 2 and 30, 5 and 10,5 and 30, and 10 and 30 year maturities.

The findings of the two cojumping tests, $\Phi_{t}^{(J)}$ and $\Phi_{t}^{(D)}$, for each bond and futures maturity pair are presented in Table 3 for 1, 5, and 10 minute sampling frequencies. Column (1) gives the number of days on which the null of cojumping is rejected using the $\Phi_{t}^{(J)}$ test, and column (3) gives the number of days when the null of no cojumping is rejected using the $\Phi_{t}^{(D)}$ test. When $\Phi_{t}^{(J)}$ is accepted and $\Phi_{t}^{(D)}$ rejected the tests consistently find cojumping, as shown in column (5). The occurrences when the tests consistently find no cojumps, when $\Phi_{t}^{(J)}$ is accepted and $\Phi_{t}^{(D)}$ rejected, are shown in column (7).

Consider first the results of the tests for spot and futures maturity pairs. Rejection of the null of cojumping increases monotonically with increasing maturity in the Treasury bonds - which means there is more evidence of cojumping at shorter maturities. To illustrate consider the 1 minute frequency in Table 3. The null of cojumping, using $\Phi_{t}^{(J)}$, is rejected in $4.4 \%$ of the total 1230 days for the 2 year maturity, and $61.5 \%$ of 1230 days for the 30 year maturity. The 5 and 10 year maturities lie between these extremes. The same pattern may be found for other sampling frequencies. The rejection frequency for the null of common jumps also seems to largely decline with sampling frequency, although this is not strongly evident in the 2 year maturity. In summary there is more evidence of cojumping at shorter maturities and higher sampling frequencies using the cojumping test.

The disjoint test, however, based on the null of disjoint jumps, $\Phi_{t}^{(D)}$, does not display a monotonicity with maturity. For example, at the 1 minute frequency in Table 3 the 
null of disjoint jumping is rejected in $88.5 \%$ of 1230 days for the 2 year maturity, and $71.4 \%$ of 1230 days for the 5 year maturity - but for the 30 year maturity the disjoint jumps are rejected in $73.2 \%$ jump days. However, there is evidence of monotonicity with the sampling frequency. Using the 5 year maturity as an example, the rejection of the disjoint null decreases from $71.4 \%$ of days at 1 minute sampling to $9.6 \%$ of days at 10 minute sampling. Thus there is less evidence of disjoint jumps at higher sampling frequencies.

Thus the cojumping and disjoint tests both support the existence of more common jumping (fewer disjoint jumps) at higher frequency of sampling, and less cojumping at lower sampling frequencies. A direct relationship with maturity is not as clear in the disjoint test. Jacod and Todorov present evidence that the $\Phi_{t}^{(D)}$ test is undersized.

The two cojumping tests have an area of disagreement, when either both reject their respective null hypotheses or both accept. The prevalence of these occurrences are recorded in columns (9) and (11) of the tables, and are clearly well in excess of the type I and type II errors expected. The prevalence of both tests rejecting the null hypothesis (that is a rejection of the null of cojumping using $\Phi_{t}^{(C J)}$ and a rejection of the null of disjoint jumping using $\left.\Phi_{t}^{(D)}\right)$ is monotonic with maturity structure and sampling frequency, with the exception of the 2 year spot and futures contracts at 1 minute sampling frequency. We consider this issue more fully in Section 5.

\subsection{Bivariate Test: Term Structure}

Results of the bivariate test for the term structure are summarized for the three sampling frequencies in Table 4 for both spot and futures contracts. The left and right hand side panels of the Table demonstrate the results when both nulls indicate joint (common arrival) or disjoint (no common arrival) jumps for all maturity pairs across the yield curve. Joint jumps occur most frequently at the short end of the maturity structure comprising the 2 and 5 year maturities. This holds for both spot and futures markets regardless of the sampling frequency. For instance, Table 4 shows that the 2 and 5 year bonds are cojumping on 976, 371 and 153 days out of total 1230 days at 1, 5 and 10 minute sampling frequencies, respectively, showing the highest proportions among all possible maturity pairs. The 2 and 30 year maturities jump jointly fairly frequently as well with the proportions higher than the ones of the short maturities. As in Dungey et al. (2009a), the term structure demonstrates more jumping behavior at the ends than in middle maturities, reflecting elements of both liquidity preference and preferred habitat theory.

The smallest number of days containing joint jumps is found for the maturity pairs when one of the assets represents the longest end of the maturity structure -30 and 10 year maturity pairs and 30 and 5 year maturity pairs. At the same time, 30 year 
maturity in conjunction with the 5 or 10 year maturities tend to jump disjointly more often than other pairs. The cases when both nulls disagree have patterns similar to the ones in Section 4.2.

To examine the results of the Sections 4.2 and 4.3 more carefully the next two sections explore first, the sampling properties of the tests by extending the Monte Carlo experiment of Jacod and Todorov (2009) to more closely resemble the characteristics of the current problem, and second, the relationship of the cojumping behavior with news announcements in US markets. This builds on a large existing body of work on the relationship between price changes in US Treasury markets and scheduled macroeconomic news releases; see Fleming and Remolona (1999), Green (2004), Simpson and Ramchander (2004), Andersen et al. (2007b).

\section{$5 \quad$ Finite Sample Properties}

\subsection{Simulation Design}

Jacod and Todorov (2009) examine the finite sample properties of their test under the assumption that the two series are uncorrelated and have the same jump intensity. The data considered in this paper are highly correlated and have different jump intensities. Consequently, we extend the Monte Carlo of Jacod and Todorov (2009) accordingly. Two data generating processes for the $\log$ price process, $X_{t}$ are implemented. The first is a constant volatility jump diffusion model originally designed by Jacod and Todorov (2009), and the second a stochastic volatility jump diffusion model, as in Andersen et al. (2010), Chernov et al. (2003), Andersen et al. (2002). The constant volatility process, CVP, is defined as:

CVP: $\quad d X_{i, t}=\sigma_{i} d W_{i, t}+\alpha_{i} \int_{\mathbb{R}} x_{i} \lambda_{i}\left(d t, d x_{i}\right)+\alpha_{3} \int_{\mathbb{R}} x_{3} \lambda_{3}\left(d t, d x_{3}\right), i=\{1,2\}$,

where $W_{t}^{i}$ is a Brownian motion, $\operatorname{cor}\left(W^{1}, W^{2}\right)=\rho_{1} ; \lambda_{1}, \lambda_{2}$ and $\lambda_{3}$ are the Poisson measures; $\sigma_{i}$ is a constant volatility factor.

The stochastic volatility jump diffusion model, SVP, has the form:

$$
\begin{array}{ll}
\text { SVP: } & d X_{i, t}=\exp \left(\beta_{0}+\beta_{i} v_{i, t}\right) d W_{i, t}+\alpha_{i} \int_{\mathbb{R}} x_{i} \lambda_{i}\left(d t, d x_{i}\right)+\alpha_{3} \int_{\mathbb{R}} x_{3} \lambda_{3}\left(d t, d x_{3}\right) \\
& d v_{i, t}=\alpha_{v} v_{i, t} d t+d W_{v_{i}, t}, i=\{1,2\},
\end{array}
$$

where $W_{t}$ is the standard Brownian motion; $\operatorname{cor}\left(W_{i}, W_{v_{1}}\right)=\rho_{i}$ is the leverage correlation; $\operatorname{cor}\left(W_{1}, W_{2}\right)=\rho$ is the correlation between returns; $v_{t}$ is the stochastic volatility component and $\lambda_{1}, \lambda_{2}$ and $\lambda_{3}$ are the Poisson measures. Following Jacod and Todorov (2009) we set $\alpha_{v}=0.1, \beta_{0}=0, \beta_{i}=0.125$ and in line with Veraart $(2010), \rho_{i}=-0.62$.

The three jump components of the process (5) are represented by two disjoint jump components and a common jump component premultiplied by $\alpha_{1}, \alpha_{2}$ and $\alpha_{3}$, respectively. 
The number of jumps in each component is simulated from a Poisson distribution with parameter $\lambda$ and is uniformly distributed on the whole time interval. The parameter $\lambda$ is chosen to reflect the lowest of the rejection frequencies in the univariate tests of the data given in Table 2. The jump sizes are drawn from a $N(0,1)$ distribution. As US Treasury futures and spot prices are characterized by high correlations we trial values of $\rho$, the correlation of the continuous part of the process, of 1.00 and 0.95 . The results were not qualitatively different and only the $\rho=1$ outcomes are reported here. We simulate 5000 replications from the processes (5) and (6) with one increment per minute for a trading day of 600 minutes, consistent with the dataset in Section $4 .^{3}$

The first three columns of Table 5 shows the parameter values of the 16 cases we consider when $\rho=1$. Intensities $\lambda_{1}$ and $\lambda_{2}$ corresponding to the disjoint components of the DGP (5) are 1:1 (this is the case studied by Jacod and Todorov, 2009), 2:1, 5:1 and 10:1, and the intensity $\lambda_{3}$ is equal to $\lambda_{1}$ in all simulation scenarios. Constant volatility factors $\sigma_{1}$ and $\sigma_{2}$ are equal to $8 \times 10^{-5}$ in all simulations.

\subsection{Size and Power}

Table 5 reports results for the case of the $1 \%$ true size tests. This significance level is reported for consistency with the application, but simulations at higher significance levels produce similar analytical results. The BNS univariate jumps test reported in columns (4) and (7) of Table 5 is oversized, consistent with literature on the univariate jump test properties (e.g. Huang and Tauchen, 2005), and more so in the SVP than CVP, which may be due to a volatility feedback effect when negative returns are associated with higher volatility. As the intensity of the jumps increases, the test size rises, indicating that the relatively small jumps are difficult to distinguish from the Wiener process. ${ }^{4}$

Under the null of cojumping the bivariate test is oversized for both DGPs as reported in columns (5) and (8) of Table 5. This improves with smaller values of the $\alpha$ parameters. The disjoint jumping test is undersized, as reported in columns (6) and (9).

Table 5 also presents the power properties of the three test statistics. Larger jump size and higher jump intensity have a positive effect on the univariate test power as shown in Columns (10) and (13). The cojumping test has relatively low power for high values of the $\alpha$ parameters, and as with the size results for this test, power improves as the sizes of the jump, the $\alpha$ parameters, increase. The disjoint test has good power in all experiments, columns (12) and (15).

The results of the Monte Carlo experiment have confirmed earlier work that the BNS

\footnotetext{
${ }^{3}$ To make the CVP and SVP processes comparable across simulations the Brownian motion innovations to the price process of equation (6) are rescaled by a factor of 120 .

${ }^{4} \mathrm{~A}$ further Monte Carlo examined the small sample properties of the univariate jump test of AïSahalia and Jacod (2009). The test consistently overrejects the null of no jumps, which is a consequence of the far fewer sample observations per day in our scenario than the 1, 4 and 15 second sampling frequencies suggested in Aït-Sahalia and Jacod (2009). Results are available on request.
} 
univariate test is somewhat oversized. The Jacod and Todorov common jumps test is also oversized with both size and power improved by higher jump sizes, while the disjoint test has good power properties, but is somewhat undersized. These results are consistent with those at 5\% and 10\% significance levels. These Monte Carlo results do not suggest that the contradictory results between the two tests observed in Section 4.2 are the result of test performance. Consequently, we next turn to relating the occurrence of jumps, and contradictory results in the bivariate jumps tests, to the presence of news announcements.

\section{Cojumps and News}

It is well known that jumps often occur in association with a news event, in particular with surprises associated with prescheduled US news releases, see Lahaye et al. (2010), Andersen et al $(2007 \mathrm{a}, \mathrm{b})$. We use a set of 23 major US macroeconomic news announcements, consistent with Simpson and Ramchander (2004) and Dungey et al. (2009a). ${ }^{5}$ Of the 1230 trading days, 702 days, or $57 \%$, contain scheduled macroeconomic news announcements.

The news surprise data for the announcements are drawn from Bloomberg and standardized across the sample. A simple cross tabulation with the jump test results suggests a strong correlation between the jump behavior and the announcement of non-farm payrolls data. Non-farm payroll releases are known to be the news release which most affects US Treasury markets; Fleming and Remolona (1999) and Dungey et al. (2009a), although Jiang and Yan (2009) find PPI as their most important event. Hence it is not surprising that if arbitrage opportunities exist between futures and spot markets they are likely to occur around surprises emanating from non-farm payrolls data. In the current sample the non-farm payrolls data were released 59 times, producing a distribution of surprises shown in Figure 2. There were more negative than positive surprises, but no particularly large negative outlier is detected.

To formally evaluate the relationship between jump days and prescheduled news announcements, we estimate a panel logit model on the probability of observing either a jump day, $J D_{i t}$, or the probability of observing a conflicting day, $C D_{i t}$, (i.e. the day when two bivariate nulls disagree) for maturities $i=2,5,10,30$ for $t=1, \ldots, 1230$. In the initial specification we examine whether the presence of news, denoted by the variable News $s_{t}$ which takes the value of 1 in the presence of news and 0 otherwise, is significant as a determinant of the probability of jumps or conflicting results. To account for possible effects of futures contract rollovers a dummy, $\operatorname{Exp}_{i, t}$ equals one on the last day of trade for a given futures contract and zero otherwise. Two such dummies are necessary as

\footnotetext{
${ }^{5}$ The news announcements are: auto sales, business inventory, capacity utilization, construction spending, consumer credit, CPI, durable goods orders, factory orders, GDP, hourly earnings, housing starts, industrial production, leading indicators, new home sales, non-farm payrolls, personal consumption, personal income, PPI, retail sales, trade balance, unemployment, US NAPM, US Treasury Budget.
} 
expiry dates are the same for 10 and 30 year contracts and for 2 and 5 year contracts $^{6}$. Day of the week dummies variables $D_{j t}, j=1,2,3,4$ are included, normalizing on Friday. Different maturities have different jump activities therefore we specify a random effects model that accounts for heterogeneity between different maturities ${ }^{7}$ :

$$
\begin{aligned}
J D(C D)_{i t}= & \beta_{0}+\beta_{1} N e w s_{t}+\beta_{3} \operatorname{Exp}_{i t \mid i=2,5} \\
& +\beta_{4} \operatorname{Exp}_{i t \mid i=10,30}+\Sigma_{j=5}^{8} \beta_{j} D_{j t}+\varepsilon_{i t}, \\
\varepsilon_{i t}= & \tau_{i}+e_{i t},
\end{aligned}
$$

where $\tau_{i}$ and $e_{i t}$ are two $i i d$ series with zero mean and constant variances. To extend this further, the News $s_{t}$ variable is supplemented by the standardized surprise in non-farm payrolls releases, $N F P_{t}$ (shown in Figure 2), and the standardized news surprise for all other news announcements, Surp $_{t}$.

$$
\begin{aligned}
J D(C D)_{i t}= & \beta_{0}+\beta_{1} \text { News }_{t}+\beta_{2} N F P_{t}+\beta_{3} \operatorname{Surp}_{t}+\beta_{4} \operatorname{Exp}_{i t \mid i=2,5} \\
& +\beta_{5} \operatorname{Exp}_{i t \mid i=10,30}+\Sigma_{j=6}^{9} \beta_{j} D_{j t}+\varepsilon_{i t}, \\
\varepsilon_{i t}= & \tau_{i}+e_{i t}
\end{aligned}
$$

Similarly, we estimate two panel logit models for the term structure of US Treasury bonds and futures, where the dependent variable $J D_{i t}$ denotes cojumps between maturities $i$ and $l$. An additional independent variable in equation (10) is a set of maturity dummies, $M_{j t}, j=i, l$, with the 30 year bond taken as the omitted category. These take the of value 1 when either of the maturity pair under consideration involves that maturity, so for jumps considered in the combination of the 2 and 5 year contracts, $M_{2, t}=M_{5, t}=1$. Futures contract expiry dummies are also included in the specification for futures only:

$$
\begin{aligned}
J D_{i t}\left(C D_{i t}\right)= & \beta_{0}+\beta_{1} \text { News }_{t}+\beta_{2} N F P_{t}+\beta_{3} \operatorname{Surp}_{t}+\beta_{4} \operatorname{Exp}_{i t \mid i=2,5} \\
& +\beta_{5} \operatorname{Exp}_{i t \mid i=10,30}+\Sigma_{j=6}^{9} \beta_{j} D_{j t}+\Sigma_{j=10}^{12} \beta_{j} M_{j t}+\varepsilon_{i l t}, \\
\varepsilon_{i t}= & \tau_{i}+e_{i t},
\end{aligned}
$$

Panel I of Table 6 reports results of estimating equations (7) and (10) with the bivariate Newst dummy. They reveal a significant positive relationship between the presence of scheduled macroeconomic news and cojump days in both the maturity matched spot and futures pairs, and in the term structure of either spot or futures. In the case of the

\footnotetext{
${ }^{6}$ The 2 and 5 year contracts expire on the last business day of the contract month, the 10 and 30 year contracts expire 7 business days before the last business day of the contract month. See www.cmegroup.com for further details. A number of robustness checks were conducted for the expiry dummy. Examination of the trade data suggests increased volume and volatility some $20 \pm 2$ trading days before the expiry of the 2 and 5 year contracts and some $15 \pm 2$ days before the expiry of the 10 and 30 year maturity contracts. Dummies based on these timings were also insignificant, and are not reported in the paper.

${ }^{7}$ The Hausman test confirms the choice of a random effects specification.
} 
spot and future maturity pairs the probability of observing a jump day increases by $2.8 \%$ given there is a prescheduled macroeconomic news announcement. For the term structure results the probability of a common jump is increased by $4.4 \%$ in the spot market and $1.0 \%$ in the futures market. The presence of macroeconomic news also results in a statistically significant $2.3 \%$ increase in the probability of the bivariate tests disagreeing for spot and futures pairs.

The presence of the long end futures expiry date is significant for the maturity pairs specification in Panel I. The significance of the day of the week dummies varies, but in general Mondays have a positive impact on the probability of observing a common jump, confirming the information that arrives after the weekend is important in explaining the jumps.

When the News $s_{t}$ dummy is augmented by the news surprise for all news announcements, as in equations (9) and (10) it retains its statistical significance. However, a further decomposition, reported in Panel II of Table 6 reveals greater detail, by allowing for asymmetric responses to positive and negative non-farm payroll surprises (asymmetric responses to general news surprises were not empirically supported). In each of the cases examined in Table 6 Panel II the presence of a negative or positive non-farm payrolls surprise statistically increases the probability of observing cojumps, and of observing a conflicting result in the jumps tests. In the case of maturity pairs of spot and futures contracts a positive and a negative non-farm payrolls news surprises increase the probability of a cojump by $22.2 \%$ and $19.5 \%$, respectively. The probability of a contradictory test result is increased by $6.4 \%$ and $6.3 \%$ in the case of a positive or a negative non-farm payroll surprise. Thus, the presence of a non-farm payroll surprise is more likely to cause a cojump, than a conflicting day. For the term structure, both positive and negative surprises are statistically significant. For the futures term structure the magnitude of the positive non-farm payroll surprise effect is more than two times higher than that of the negative surprise and statistically different. In the case of the bond term structure there is a significant effect of the macro news of around $20 \%$ for either positive or negative surprises, confirming findings in the existing literature (see Dungey et al., 2009a). Wald tests indicate significant differences between the coefficients on positive and negative surprises in the specifications for the futures term structure, but not for the remaining specifications.

While the finding that news results are important in the univariate jumps literature is not unusual, here the emphasis is on how the news impacts significantly on the cases where the market data are not clearly signalling the jump behavior of the prices. These cases, which seem to be associated with the case of worse than anticipated news releases, are interesting in that they represent periods when hedging may be difficult. ${ }^{8}$

\footnotetext{
${ }^{8}$ Jiang, Lo and Verdhalan (2010) suggest that liquidity factors may also be important in these circumstances, however, the expandable limit order nature of the eSpeed database makes the construction of
} 


\section{Conclusions}

The presence of price discontinuities in high frequency financial market data is well documented in the univariate case. However, many interesting questions concern the presence of contemporaneous price disruptions across multiple assets. In a hedging framework an obvious question is the extent to which spot and future prices exhibit such behavior. Recently, Jacod and Todorov (2009) have developed a bivariate test for contemporaneous jumps across two series using a pair of tests - one of which has a null of cojumping and one of which the null of disjoint jumps. This paper considers the cojumping behavior of spot and future contracts for US Treasury contracts in maturity pairs, and across the term structure. The bivariate tests indicate that the detection of cojumping is increasing with sampling frequency. The test with the null of cojumping finds a monotonic relationship between cojumping and maturity structure - more cojumps are detected for lower maturity contracts in both futures and spot contracts for maturity pairs, or within the same market across the term structure. However, the test with a null of disjoint jumps (that is jumps on the same day but different time intervals within that day) find no clear relationship with maturity structure.

As the two cojumping tests disagree more than statistically expected, the small sample properties of the tests were confirmed under the conditions of highly correlated series of different intensities present in this data. The disjoint test is found to be slightly undersized but with good power.

Prescheduled macroeconomic news events increase the probability of cojumping behavior, and more specifically negative surprises in non-farm payrolls data increase the probability of observing a cojump in maturity matched pairs of spot and futures contracts for US Treasuries. The presence of negative surprises in non-farm payrolls is also associated with a lesser increase in the probability of the cojumping tests being unable to distinguish whether the two price series are jumping contemporaneously or with some time separation. Non-farm payroll surprises increase the probability of jump behavior in both spot and futures contracts for US Treasuries. They also increase the probability of a lack of clear signal as to whether a jump in one asset price is likely to be immediately accompanied by a jump in the other. The increase in probability of cojumping is higher than the probability of observing a conflicting result. Overall, the results indicate the importance of non-farm payrolls releases to active portfolio management.

an order book similar to that used in their analysis uniformative in this case, see Dungey et al. (2009b) and Boni and Leach (2004) for a description of the expandable limit order book. 


\section{References}

[1] Aït-Sahalia, Y. and J. Jacod (2009), "Testing for Jumps in a Discretely Observed Process", Annals of Statistics, 37, 184-222.

[2] Andersen, T. G., T. Bollerslev, P. Frederiksen and M. Ø. Nielsen (2010), "Continuous-Time Models, Realized Volatilities, and Testable Distributional Implications for Daily Stock Returns", Journal of Applied Econometrics, 25(2), 233-261.

[3] Andersen, T. G., T. Bollerslev and F. X. Diebold (2007a), "Roughing it Up: Including Jump Components in the Measurement, Modelling and Forecasting of Return Volatility", The Review of Economics and Statistics, 89, 4, 701-720.

[4] Andersen, T. G. and Bollerslev, T., Diebold, X. and Vega, C. (2007b), "Real-Time Price Discovery in Global Stock, Bond and Foreign Exchange Markets", Journal of International Economics, 73, 251-277.

[5] Andersen, T. G., L. Benzoni and J. Lund (2002), "An Empirical Investigation of Continuous-Time Equity Return Models", Journal of Finance, 57, 1047-1091.

[6] Bandi, F. M., and J. R. Russell (2006), "Separating Micro Structure Noise from Volatility", Journal of Financial Economics, 79, 655-692.

[7] Barndorff-Nielsen, O. E. and N. Shephard (2006), "Econometrics of Testing for Jumps in Financial Economics Using Bipower Variation", Journal of Financial Econometrics, 4, 1-30.

[8] Barndorff-Nielsen, O. E. and N. Shephard (2004), "Measuring the Impact of Jumps in Multivariate Price Process Using Bi-Power Covariation", manuscript.

[9] Boni, L. and C. Leach (2004), "Expandable Limit Order Markets", Journal of Financial Markets, 7, 145-185.

[10] Chen, Y. and Y. Gau (2010), "News Announcements and Price Discovery in Foreign Exchange Spot and Futures Markets", Journal of Banking and Finance, 34, 16281636.

[11] Chernov, M., A. R. Gallant, E. Ghysels and G. Tauchen (2003), "Alternative Models for Stock Price Dynamics", Journal of Econometrics, 116, 225-257.

[12] Dungey, M., M. McKenzie and V. Smith (2009a), "News, No-News and Jumps in the US Treasury Market", Journal of Empirical Finance, 16, 430-445.

[13] Dungey, M., Henry, O. and M. McKenzie (2009b), "From Trade-to-Trade in US Treasuries", manuscript.

[14] Fleming M. J. and E. M. Remolona (1999), "What Moves Bond Prices?", Journal of Portfolio Management, 25, 28-38.

[15] Green, T. C. (2004), "Economic News and the Impact of Trading on Bond Prices", The Journal of Finance, 59 (3), 1201-1233.

[16] Huang, X. and G. Tauchen (2005), "The Relative Contribution of Jumps to Total Price Variance", Journal of Financial Econometrics, 3, 4, 456 - 499.

[17] Jacod, J. and V. Todorov (2009), "Testing for Common Arrivals of Jumps for Discretely Observed Multidimensional Processes", Annals of Statistics, 37 (4).

[18] Jiang, G. and Yan, S. (2009), "Linear-quadratic term structure models - Toward the understanding of jumps in interest rates", Journal of Banking and Finance, 33, 473-485. 
[19] Jiang, G., I. Lo. and A. Verdelhan (2010), "Information Shocks, Liquidity Shocks, Jumps and Price Discovery: Evidence from the U.S. Treasury Market", Journal of Financial and Quantitative Analysis, forthcoming.

[20] Lahaye, L., S. Laurent and C. Neely (2010), "Jumps, Cojumps and Macro Announcements", Journal of Applied Econometrics, forthcoming (available in early view).

[21] Lee, H.-T. (2010), "Regime Switching Correlation Hedging", Journal of Banking and Finance, forthcoming (available in early view).

[22] Lee, S. S. and P. A. Mykland (2008), "Jumps in Financial Markets: A New Nonparametric Test and Jump Dynamics", Review of Financial Studies, 21(6), 2535-2563.

[23] Lien, D. and Tse, Y. (2002), "Some Recent Developments in Futures Hedging", Journal of Economic Surveys, 16, 357-396.

[24] Mizrach, B. and C. Neely (2008), "Information Shares in the US Treasury Market", Journal of Banking and Finance, 32, 1221-1233.

[25] Spiegel, M. (2008), "Patterns in Cross Market Liquidity", Financial Research Letters, $5,2-10$.

[26] Simpson, M. W. and S. Ramchander (2004), "An Examination of the Impact of Macroeconomic News on the Spot and Futures Treasuries Markets", Journal of Futures Markets, 24 (5), 453-478.

[27] Stein, J. L. (1961), "The Simultaneous Determination of Spot and Future Prices", American Economic Review, 51, 1012-1025.

[28] Rosenberg, J. V. and L. G. Traub (2006), "Price Discovery in the Foreign Currency Futures and Spot Market", Federal Reserve Bank of New York Staff Report, No. 262.

[29] Veraart, A.E.D. (2010), "Inference for the Jump Part of Quadratic Variation of Itô Semimartingales", Econometric Theory, 26 (2), 331-368. 
Table 1:

Descriptive Statistics for Bond and Futures Returns Across Maturities and Frequencies, $2002-2006$

\begin{tabular}{|c|c|c|c|c|c|c|c|c|}
\hline \multirow[b]{2}{*}{ Maturity } & \multicolumn{4}{|c|}{ BONDS } & \multicolumn{4}{|c|}{ FUTURES } \\
\hline & Mean & St Dev & Min & Max & Mean & St Dev & Min & $\operatorname{Max}$ \\
\hline & \multicolumn{8}{|c|}{1 Minute Sampling } \\
\hline 2 year & 0.0000 & 0.006 & -2.032 & 2.032 & 0.0000 & 0.054 & -0.968 & 1.140 \\
\hline 5 year & 0.0000 & 0.012 & -2.866 & 2.913 & 0.0000 & 0.151 & -1.534 & 1.951 \\
\hline 10 year & 0.0000 & 0.018 & -1.787 & 1.703 & 0.0000 & 0.260 & -2.872 & 2.890 \\
\hline \multirow[t]{2}{*}{30 year } & 0.0000 & 0.033 & -9.564 & 9.550 & 0.0000 & 0.271 & -5.249 & 4.234 \\
\hline & \multicolumn{8}{|c|}{5 Minute Sampling } \\
\hline 2 Year & 0.0000 & 0.010 & -0.517 & 0.470 & 0.0000 & 0.077 & -0.968 & 1.140 \\
\hline 5 Year & 0.0001 & 0.024 & -0.870 & 1.234 & 0.0000 & 0.170 & -1.667 & 2.022 \\
\hline 10 Year & 0.0001 & 0.040 & -1.723 & 1.509 & 0.0000 & 0.276 & -2.604 & 2.639 \\
\hline \multirow[t]{2}{*}{30 Year } & 0.0002 & 0.071 & -9.535 & 9.550 & 0.0000 & 0.290 & -4.234 & 4.180 \\
\hline & \multicolumn{8}{|c|}{10 Minute Sampling } \\
\hline 2 Year & 0.001 & 0.014 & -0.548 & 0.544 & 0.0000 & 0.084 & -0.968 & 1.140 \\
\hline 5 Year & 0.002 & 0034 & -1.103 & 1.326 & 0.0001 & 0.176 & -1.693 & 2004 \\
\hline 10 Year & 0.002 & 0.056 & -1.549 & 1.583 & 0.0000 & 0.286 & -2.406 & 2.633 \\
\hline 30 Year & 0.003 & 0.086 & -1.979 & 1.902 & 0.0001 & 0.300 & -4.234 & 4.180 \\
\hline
\end{tabular}

Figure 1: 5 Minute Returns for 5 Year Maturity US Treasury Bonds and Futures:

1 April 2005
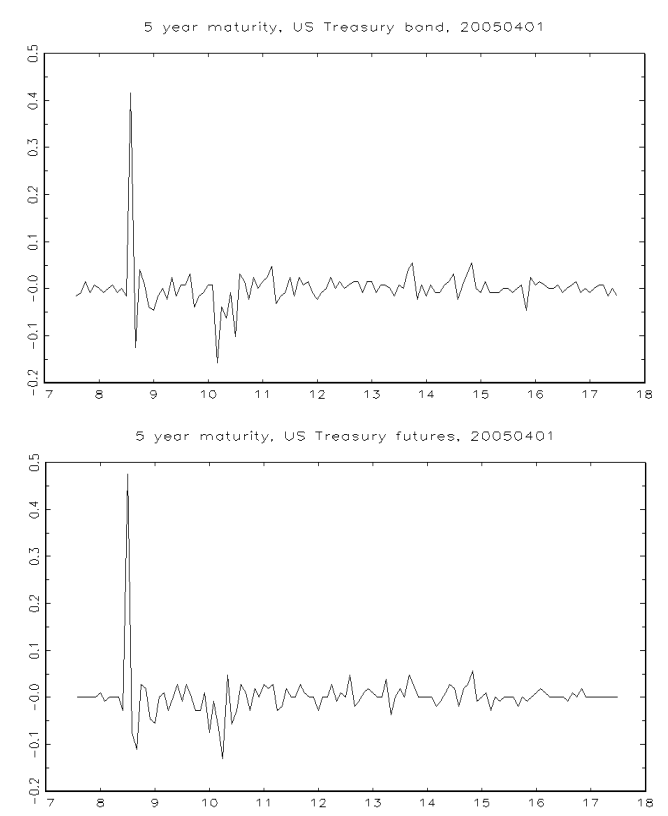

7 February 2003
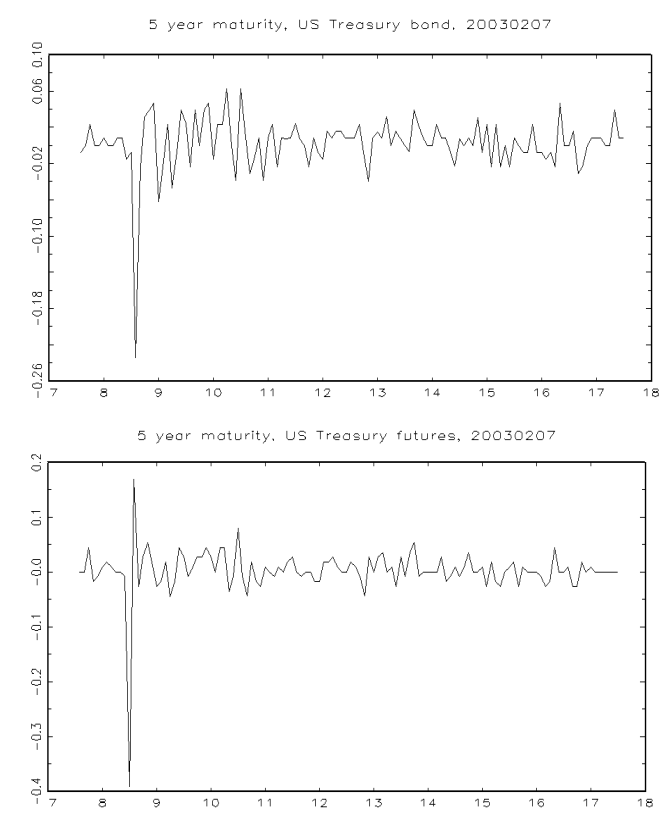
Table 2:

Results of the Univariate Test for the US Treasury Bond and Futures, January 2002 December 2006

\begin{tabular}{|c|c|c|c|c|c|c|}
\hline \multirow[b]{2}{*}{ Maturity } & \multicolumn{2}{|c|}{ BOND } & \multicolumn{2}{|c|}{ FUTURES } & \multirow{2}{*}{$\begin{array}{c}\text { No. of } \\
\text { Common } \\
\text { Jump Days }\end{array}$} & \multirow{2}{*}{$\begin{array}{c}\text { Prop. of } \\
\text { Common } \\
\text { Jump Days }\end{array}$} \\
\hline & $\begin{array}{c}\text { No. of } \\
\text { Jump Days }\end{array}$ & $\begin{array}{l}\text { Rejection } \\
\text { Frequency }\end{array}$ & $\begin{array}{c}\text { No. of } \\
\text { Jump Days }\end{array}$ & $\begin{array}{l}\text { Rejection } \\
\text { Frequency }\end{array}$ & & \\
\hline \multicolumn{7}{|c|}{1 Minute Sampling: } \\
\hline 2 Year & 1213 & 0.986 & 1222 & 0.993 & 1207 & 0.981 \\
\hline 5 Year & 1073 & 0.872 & 1198 & 0.974 & 1052 & 0.855 \\
\hline 10 Year & 1104 & 0.898 & 1166 & 0.948 & 1048 & 0.852 \\
\hline 30 Year & 1207 & 0.981 & 1128 & 0.917 & 1106 & 0.899 \\
\hline \multicolumn{7}{|c|}{5 Minute Sampling: } \\
\hline 2 Year & 916 & 0.745 & 1104 & 0.898 & 813 & 0.661 \\
\hline 5 Year & 451 & 0.367 & 728 & 0.592 & 293 & 0.238 \\
\hline 10 Year & 484 & 0.393 & 652 & 0.530 & 287 & 0.233 \\
\hline 30 Year & 574 & 0.467 & 586 & 0.476 & 298 & 0.242 \\
\hline \multicolumn{7}{|c|}{10 Minute Sampling: } \\
\hline 2 Year & 564 & 0.459 & 778 & 0.633 & 365 & 0.297 \\
\hline 5 Year & 298 & 0.242 & 347 & 0.282 & 142 & 0.115 \\
\hline 10 Year & 271 & 0.220 & 281 & 0.228 & 86 & 0.070 \\
\hline 30 Year & 273 & 0.222 & 250 & 0.203 & 87 & 0.071 \\
\hline
\end{tabular}

Figure 2: Distribution of the Standardised Non-Farm Payroll Surprises, 2001 - 2006

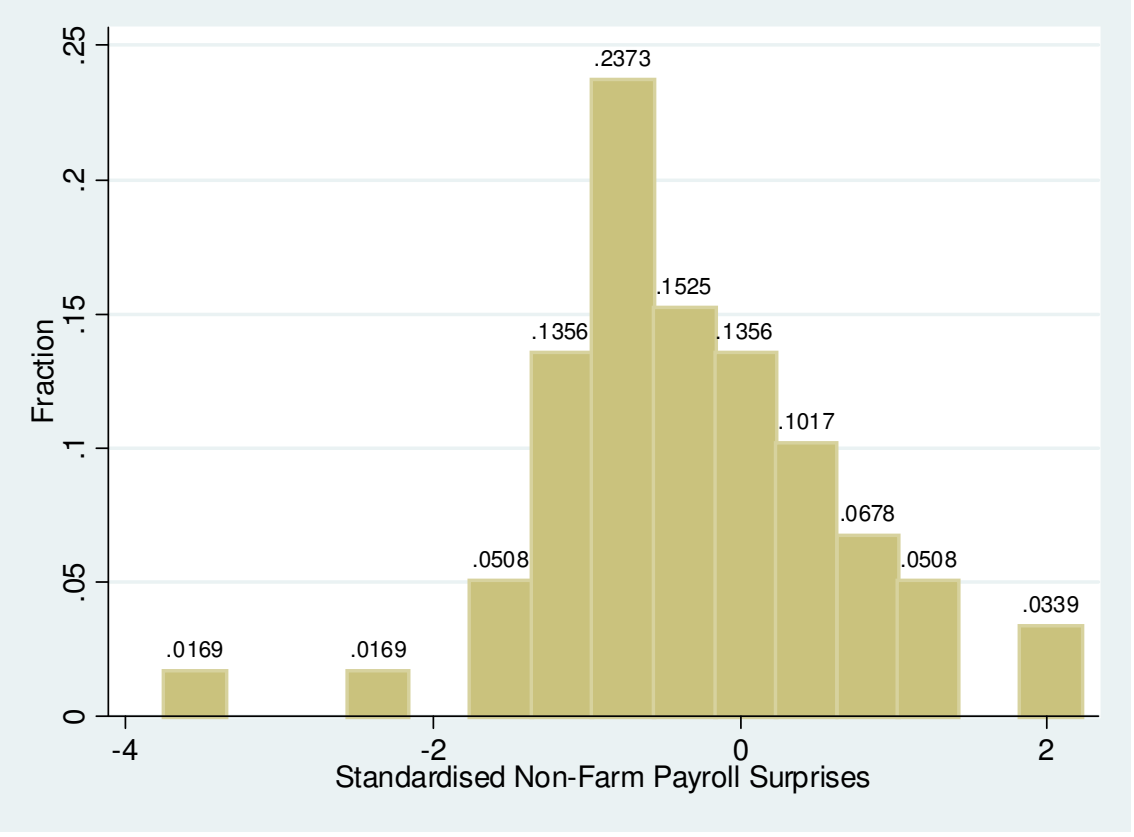


Table 3:

Results of the Bivariate Test for the Maturity Pairs of US Treasury Bond and Futures, January 2002 - December 2006

\begin{tabular}{|c|c|c|c|c|c|c|c|c|c|c|c|c|}
\hline \multirow{3}{*}{ Maturity } & \multicolumn{4}{|c|}{ Reject Ho: } & \multirow{2}{*}{\multicolumn{2}{|c|}{$\begin{array}{c}\text { Common } \\
\text { Arrival } \\
\text { of Jumps: } \\
\text { Accept } \Phi_{t}^{(j)} \\
\text { Reject } \Phi_{t}^{(d)}\end{array}$}} & \multirow{2}{*}{\multicolumn{2}{|c|}{$\begin{array}{c}\text { No Common } \\
\text { Arrival } \\
\text { of Jumps: } \\
\text { Reject } \Phi_{t}^{(j)} \\
\text { Accept } \Phi_{t}^{(d)} \\
\end{array}$}} & \multirow{2}{*}{\multicolumn{2}{|c|}{$\begin{array}{c}\text { Both Nulls } \\
\text { Cannot be } \\
\text { Rejected } \\
\text { Accept } \Phi_{t}^{(j)} \\
\text { Accept } \Phi_{t}^{(d)}\end{array}$}} & \multirow{2}{*}{\multicolumn{2}{|c|}{$\begin{array}{c}\text { Both Nulls } \\
\text { Can be } \\
\text { Rejected } \\
\text { Reject } \Phi_{t}^{(j)} \\
\text { Reject } \Phi_{t}^{(d)} \\
\end{array}$}} \\
\hline & \multicolumn{2}{|c|}{$\begin{array}{c}\text { Joint } \\
\text { Jumps, } \Phi_{t}^{(j)}\end{array}$} & \multicolumn{2}{|c|}{$\begin{array}{c}\text { Disjoint } \\
\text { Jumps, } \Phi_{t}^{(d)}\end{array}$} & & & & & & & & \\
\hline & $\begin{array}{l}\text { No. } \\
(1)\end{array}$ & $\begin{array}{l}\text { Prop. } \\
(2)\end{array}$ & $\begin{array}{l}\text { No. } \\
(3)\end{array}$ & $\begin{array}{l}\text { Prop. } \\
\text { (4) }\end{array}$ & $\begin{array}{l}\text { No. } \\
(5)\end{array}$ & $\begin{array}{l}\text { Prop. } \\
(6)\end{array}$ & $\begin{array}{l}\text { No. } \\
(7)\end{array}$ & $\begin{array}{c}\text { Prop. } \\
(8)\end{array}$ & $\begin{array}{l}\text { No. } \\
(9)\end{array}$ & $\begin{array}{c}\text { Prop. } \\
(10)\end{array}$ & $\begin{array}{l}\text { No. } \\
(11)\end{array}$ & $\begin{array}{c}\text { Prop. } \\
(12)\end{array}$ \\
\hline \multicolumn{13}{|c|}{1 minute sampling } \\
\hline 2 year & 54 & 0.044 & 1089 & 0.885 & 1047 & 0.851 & 12 & 0.010 & 106 & 0.086 & 42 & 0.034 \\
\hline 5 year & 189 & 0.154 & 878 & 0.714 & 749 & 0.609 & 60 & 0.049 & 114 & 0.093 & 129 & 0.105 \\
\hline 10 year & 466 & 0.379 & 806 & 0.655 & 471 & 0.383 & 131 & 0.107 & 111 & 0.090 & 335 & 0.272 \\
\hline 30 year & 756 & 0.615 & 900 & 0.732 & 308 & 0.250 & 164 & 0.133 & 42 & 0.034 & 592 & 0.481 \\
\hline \multicolumn{13}{|c|}{5 minute sampling } \\
\hline 2 year & 34 & 0.028 & 708 & 0.576 & 683 & 0.555 & 9 & 0.007 & 96 & 0.078 & 25 & 0.020 \\
\hline 5 year & 77 & 0.063 & 243 & 0.198 & 187 & 0.152 & 21 & 0.017 & 29 & 0.024 & 56 & 0.046 \\
\hline 10 year & 158 & 0.128 & 226 & 0.184 & 111 & 0.090 & 43 & 0.035 & 18 & 0.015 & 115 & 0.093 \\
\hline 30 year & 241 & 0.196 & 246 & 0.200 & 52 & 0.042 & 47 & 0.038 & 5 & 0.004 & 194 & 0.158 \\
\hline \multicolumn{13}{|c|}{10 minute sampling } \\
\hline 2 year & 43 & 0.035 & 328 & 0.267 & 290 & 0.236 & 5 & 0.004 & 32 & 0.026 & 38 & 0.031 \\
\hline 5 year & 65 & 0.053 & 118 & 0.096 & 69 & 0.056 & 16 & 0.013 & 8 & 0.007 & 49 & 0.040 \\
\hline 10 year & 53 & 0.043 & 75 & 0.061 & 30 & 0.024 & 8 & 0.007 & 3 & 0.002 & 45 & 0.037 \\
\hline 30 year & 74 & 0.060 & 71 & 0.058 & 12 & 0.010 & 15 & 0.012 & 1 & 0.001 & 59 & 0.048 \\
\hline
\end{tabular}


Table 4:

Results of the Bivariate Test for the Maturity Pairs Spot and Futures markets, January 2002 - December 2006

\begin{tabular}{|c|c|c|c|c|c|c|c|c|c|c|c|c|}
\hline \multirow[t]{2}{*}{ Maturity } & \multicolumn{2}{|c|}{$\begin{array}{c}\text { Common } \\
\text { Arrival } \\
\text { of Jumps: } \\
\text { Accept } \Phi_{t}^{(j)} \\
\text { Reject } \Phi_{t}^{(d)}\end{array}$} & \multicolumn{2}{|c|}{$\begin{array}{c}\text { No Common } \\
\text { Arrival } \\
\text { of Jumps: } \\
\text { Reject } \Phi_{t}^{(j)} \\
\text { Accept } \Phi_{t}^{(d)}\end{array}$} & \multicolumn{2}{|c|}{$\begin{array}{l}\text { Both Nulls } \\
\text { Can Be } \\
\text { Rejected } \\
\text { Reject } \Phi_{t}^{(j)} \\
\text { Reject } \Phi_{t}^{(d)}\end{array}$} & \multicolumn{2}{|c|}{$\begin{array}{c}\text { Common } \\
\text { Cannot be } \\
\text { Rejected } \\
\text { Accept } \Phi_{t}^{(j)} \\
\text { Accept } \Phi_{t}^{(d)}\end{array}$} & \multicolumn{2}{|c|}{$\begin{array}{c}\text { No Common } \\
\text { Can be } \\
\text { Rejected } \\
\text { Reject } \Phi_{t}^{(j)} \\
\text { Reject } \Phi_{t}^{(d)}\end{array}$} & \multicolumn{2}{|c|}{$\begin{array}{c}\text { Both Nulls } \\
\text { Can Be } \\
\text { Rejected } \\
\text { Reject } \Phi_{t}^{(j)} \\
\text { Reject } \Phi_{t}^{(d)}\end{array}$} \\
\hline & No. & Prop. & No. & Prop. & No. & Prop. & No. & Prop. & No. & Prop. & No. & Prop. \\
\hline \multicolumn{13}{|c|}{1 minute sampling } \\
\hline 2 and 5 & 976 & 0.793 & 5 & 0.004 & 42 & 0.034 & 857 & 0.697 & 26 & 0.021 & 242 & 0.197 \\
\hline 2 and 10 & 981 & 0.798 & 6 & 0.005 & 52 & 0.042 & 650 & 0.528 & 63 & 0.051 & 328 & 0.267 \\
\hline 2 and 30 & 983 & 0.799 & 23 & 0.019 & 106 & 0.086 & 557 & 0.453 & 86 & 0.070 & 377 & 0.307 \\
\hline 5 and 10 & 822 & 0.668 & 17 & 0.014 & 116 & 0.094 & 427 & 0.347 & 133 & 0.108 & 493 & 0.401 \\
\hline 5 and 30 & 784 & 0.637 & 27 & 0.022 & 207 & 0.168 & 346 & 0.281 & 151 & 0.123 & 508 & 0.413 \\
\hline 10 and 30 & 644 & 0.524 & 44 & 0.036 & 378 & 0.307 & 219 & 0.178 & 166 & 0.135 & 635 & 0.516 \\
\hline \multicolumn{13}{|c|}{5 minute sampling } \\
\hline 2 and 10 & 371 & 0.302 & 0 & 0.000 & 33 & 0.027 & 428 & 0.348 & 51 & 0.041 & 122 & 0.099 \\
\hline 2 and 10 & 369 & 0.300 & 0 & 0.000 & 46 & 0.037 & 283 & 0.230 & 52 & 0.042 & 190 & 0.154 \\
\hline 2 and 30 & 371 & 0.302 & 2 & 0.002 & 56 & 0.046 & 254 & 0.207 & 55 & 0.045 & 175 & 0.142 \\
\hline 5 and 10 & 211 & 0.172 & 0 & 0.000 & 94 & 0.076 & 161 & 0.131 & 69 & 0.056 & 198 & 0.161 \\
\hline 5 and 30 & 173 & 0.141 & 2 & 0.002 & 107 & 0.087 & 129 & 0.105 & 43 & 0.035 & 191 & 0.155 \\
\hline 10 and 30 & 137 & 0.111 & 6 & 0.005 & 158 & 0.128 & 66 & 0.054 & 60 & 0.049 & 212 & 0.172 \\
\hline \multicolumn{13}{|c|}{10 minute sampling } \\
\hline 2 and 5 & 153 & 0.124 & 0 & 0.000 & 76 & 0.062 & 142 & 0.115 & 6 & 0.005 & 74 & 0.060 \\
\hline 2 and 10 & 122 & 0.099 & 0 & 0.000 & 68 & 0.055 & 93 & 0.076 & 18 & 0.015 & 71 & 0.058 \\
\hline 2 and 30 & 98 & 0.080 & 1 & 0.001 & 69 & 0.056 & 73 & 0.059 & 13 & 0.011 & 67 & 0.054 \\
\hline 5 and 10 & 91 & 0.074 & 0 & 0.000 & 96 & 0.078 & 49 & 0.040 & 10 & 0.008 & 71 & 0.058 \\
\hline 5 and 30 & 59 & 0.048 & 0 & 0.000 & 91 & 0.074 & 28 & 0.023 & 12 & 0.010 & 65 & 0.053 \\
\hline 10 and 30 & 51 & 0.041 & 0 & 0.000 & 110 & 0.089 & 20 & 0.016 & 6 & 0.005 & 69 & 0.056 \\
\hline
\end{tabular}


Table 5:

Size and Power Properties of the Univariate and Bivariate Jump Tests Based on an Asymptotic Size of 1\%, Constant and Stochastic Volatility Models, Equivalent to 1 Minute Sampling Frequency, 5,000 Replications.

\begin{tabular}{|c|c|c|c|c|c|c|c|c|c|c|c|c|c|c|}
\hline \multirow{2}{*}{\multicolumn{3}{|c|}{$\begin{array}{c}\text { Parameters } \\
\rho=1\end{array}$}} & \multicolumn{6}{|c|}{ Size } & \multicolumn{6}{|c|}{ Power } \\
\hline & & & \multicolumn{3}{|c|}{ CVP } & \multicolumn{3}{|c|}{ SVP } & \multicolumn{3}{|c|}{ CVP } & \multicolumn{3}{|c|}{ SVP } \\
\hline $\begin{array}{l}\alpha_{3} \\
(1)\end{array}$ & $\begin{array}{c}\alpha_{1,2} \\
(2)\end{array}$ & $\begin{array}{c}\lambda_{1: 2} \\
(3)\end{array}$ & $\begin{array}{c}J S_{t} \\
(4)\end{array}$ & $\begin{array}{c}T_{t}^{(j)} \\
(5)\end{array}$ & $\begin{array}{c}T_{t}^{(d)} \\
(6)\end{array}$ & $\begin{array}{c}J S_{t} \\
(7)\end{array}$ & $\begin{array}{c}T_{t}^{(j)} \\
(8)\end{array}$ & $\begin{array}{c}T_{t}^{(d)} \\
(9)\end{array}$ & $\begin{array}{l}J S_{t} \\
(10)\end{array}$ & $\begin{array}{l}T_{t}^{(j)} \\
(11)\end{array}$ & $\begin{array}{l}T_{t}^{(d)} \\
(12)\end{array}$ & $\begin{array}{l}J S_{t} \\
(13)\end{array}$ & $\begin{array}{l}T_{t}^{(j)} \\
(14)\end{array}$ & $\begin{array}{l}T_{t}^{(d)} \\
(15)\end{array}$ \\
\hline 0.6 & 0.6 & $1: 1$ & 0.018 & 0.334 & 0.001 & 0.114 & 0.340 & 0.001 & 0.959 & 0.666 & 0.999 & 0.855 & 0.660 & 0.999 \\
\hline 0.6 & 0.6 & $2: 1$ & 0.020 & 0.333 & 0.000 & 0.108 & 0.343 & 0.000 & 0.963 & 0.667 & 1.000 & 0.898 & 0.657 & 1.000 \\
\hline 0.6 & 0.6 & $5: 1$ & 0.028 & 0.354 & 0.000 & 0.110 & 0.364 & 0.000 & 0.958 & 0.646 & 1.000 & 0.933 & 0.636 & 1.000 \\
\hline 0.6 & 0.6 & 10:1 & 0.030 & 0.347 & 0.000 & 0.106 & 0.357 & 0.000 & 0.956 & 0.653 & 1.000 & 0.946 & 0.643 & 1.000 \\
\hline 0.6 & 0.2 & $1: 1$ & 0.018 & 0.333 & 0.001 & 0.114 & 0.336 & 0.001 & 0.911 & 0.667 & 0.999 & 0.829 & 0.664 & 0.999 \\
\hline 0.6 & 0.2 & $2: 1$ & 0.020 & 0.333 & 0.000 & 0.108 & 0.343 & 0.000 & 0.917 & 0.667 & 1.000 & 0.882 & 0.657 & 1.000 \\
\hline 0.6 & 0.2 & $5: 1$ & 0.028 & 0.355 & 0.000 & 0.110 & 0.362 & 0.000 & 0.915 & 0.645 & 1.000 & 0.923 & 0.638 & 1.000 \\
\hline 0.6 & 0.2 & 10:1 & 0.030 & 0.346 & 0.000 & 0.106 & 0.356 & 0.000 & 0.907 & 0.654 & 1.000 & 0.940 & 0.644 & 1.000 \\
\hline 0.2 & 0.6 & $1: 1$ & 0.018 & 0.086 & 0.001 & 0.114 & 0.097 & 0.001 & 0.912 & 0.914 & 0.999 & 0.816 & 0.903 & 0.999 \\
\hline 0.2 & 0.6 & $2: 1$ & 0.020 & 0.092 & 0.000 & 0.108 & 0.105 & 0.001 & 0.918 & 0.908 & 1.000 & 0.859 & 0.895 & 0.999 \\
\hline 0.2 & 0.6 & $5: 1$ & 0.028 & 0.103 & 0.001 & 0.110 & 0.111 & 0.001 & 0.922 & 0.897 & 0.999 & 0.892 & 0.889 & 0.999 \\
\hline 0.2 & 0.6 & 10:1 & 0.030 & 0.102 & 0.000 & 0.106 & 0.107 & 0.000 & 0.914 & 0.898 & 1.000 & 0.902 & 0.893 & 1.000 \\
\hline 0.2 & 0.2 & $1: 1$ & 0.018 & 0.071 & 0.001 & 0.114 & 0.076 & 0.001 & 0.858 & 0.929 & 0.999 & 0.786 & 0.924 & 0.999 \\
\hline 0.2 & 0.2 & $2: 1$ & 0.020 & 0.085 & 0.000 & 0.108 & 0.091 & 0.000 & 0.868 & 0.915 & 1.000 & 0.840 & 0.909 & 1.000 \\
\hline 0.2 & 0.2 & $5: 1$ & 0.028 & 0.092 & 0.000 & 0.110 & 0.098 & 0.000 & 0.871 & 0.908 & 1.000 & 0.876 & 0.902 & 1.000 \\
\hline 0.2 & 0.2 & 10:1 & 0.030 & 0.093 & 0.000 & 0.106 & 0.095 & 0.000 & 0.861 & 0.907 & 1.000 & 0.891 & 0.905 & 1.000 \\
\hline
\end{tabular}


Table 6:

Results of the Panel Logit Random Effects Model Estimation, Marginal Effects, 5 Minute Sampling Frequency

\begin{tabular}{|c|c|c|c|c|c|c|}
\hline & \multicolumn{3}{|c|}{$\begin{array}{l}\text { Common Jump Days } \\
\end{array}$} & \multicolumn{3}{|c|}{$\begin{array}{l}\text { Conflicting Jump Days } \\
\end{array}$} \\
\hline & \multirow{2}{*}{$\begin{array}{c}\text { Maturity Pairs } \\
\text { Spot and Futures }\end{array}$} & \multicolumn{2}{|c|}{ Term Structure } & \multirow{2}{*}{$\begin{array}{l}\text { Maturity Pairs } \\
\text { Spot and Futures }\end{array}$} & \multicolumn{2}{|c|}{ Term Structure } \\
\hline Spo & & Spot & Futures & & Spot & Futures \\
\hline \multicolumn{7}{|l|}{ Panel I: } \\
\hline \multirow[t]{2}{*}{ News } & $0.028 * * *$ & $0.044^{*}$ & 0.010 & $0.023^{* *}$ & $0.029 *$ & $0.026^{*}$ \\
\hline & $(0.017)$ & $(0.012)$ & $(0.013)$ & $(0.011)$ & $(0.006)$ & $(0.009)$ \\
\hline \multirow{2}{*}{$D_{M o}$} & $0.086^{*}$ & 0.007 & $0.123^{*}$ & 0.000 & $-0.034^{*}$ & $0.028 * * *$ \\
\hline & $(0.029)$ & $(0.019)$ & $(0.022)$ & $(0.011)$ & $(0.006)$ & $(0.016)$ \\
\hline \multirow{2}{*}{$D_{\text {Tue }}$} & -0.010 & $-0.063^{*}$ & 0.027 & $-0.020 * * *$ & $-0.027^{*}$ & 0.011 \\
\hline & $(0.023)$ & $(0.016)$ & $(0.019)$ & $(0.011)$ & $(0.005)$ & $(0.014)$ \\
\hline \multirow{2}{*}{$D_{W e d}$} & -0.011 & $-0.078^{*}$ & $0.056^{*}$ & -0.005 & $-0.028^{*}$ & $0.027^{* *}$ \\
\hline & $(0.023)$ & $(0.015)$ & $(0.019)$ & $(0.009)$ & $(0.005)$ & $(0.014)$ \\
\hline \multirow[t]{2}{*}{$D_{T h u}$} & $-0.070^{*}$ & $-0.069^{*}$ & -0.015 & $-0.028^{* *}$ & $-0.035^{*}$ & -0.013 \\
\hline & $(0.024)$ & $(0.015)$ & $(0.019)$ & $(0.013)$ & $(0.005)$ & $(0.013)$ \\
\hline \multirow[t]{2}{*}{ Expiry $_{10,30}$} & $0.121^{* * *}$ & - & 0.014 & 0.033 & - & 0.026 \\
\hline & $(0.064)$ & - & $(0.049)$ & $(0.029)$ & - & $(0.037)$ \\
\hline \multirow[t]{2}{*}{ Expiry $_{2,5}$} & -0.017 & - & 0.033 & - & - & -0.047 \\
\hline & $(0.079)$ & - & $(0.059)$ & - & - & $(0.034)$ \\
\hline \multirow[t]{2}{*}{$M_{2}$} & - & $0.107^{*}$ & $0.210^{*}$ & - & $-0.069^{*}$ & $-0.036^{*}$ \\
\hline & - & $(0.013)$ & $(0.014)$ & - & $(0.007)$ & $(0.010)$ \\
\hline \multirow[t]{2}{*}{$M_{5}$} & - & -0.014 & $0.092^{*}$ & - & $-0.030^{*}$ & $-0.026^{*}$ \\
\hline & - & $(0.013)$ & $(0.014)$ & - & $(0.006)$ & $(0.010)$ \\
\hline \multirow[t]{2}{*}{$M_{10}$} & - & 0.002 & $0.048^{*}$ & - & -0.008 & 0.009 \\
\hline & - & $(0.013)$ & $(0.014)$ & - & $(0.006)$ & $(0.010)$ \\
\hline \multicolumn{7}{|l|}{ Panel II: } \\
\hline \multirow[t]{2}{*}{ News } & 0.023 & 0.038* & 0.007 & $0.020 * *$ & $0.022^{*}$ & $0.023^{*}$ \\
\hline & $(0.017)$ & $(0.012)$ & $(0.013)$ & $(0.010)$ & $(0.006)$ & $(0.009)$ \\
\hline \multirow{2}{*}{$S u r p \_e x l \_n f p$} & -0.003 & -0.012 & -0.006 & -0.001 & $0.006^{* *}$ & -0.003 \\
\hline & $(0.012)$ & $(0.009)$ & $(0.009)$ & $(0.005)$ & $(0.003)$ & $(0.006)$ \\
\hline Non-farm pos & $0.221^{*}$ & $0.190^{*}$ & $0.222^{*}$ & $0.064^{* *}$ & $0.098^{*}$ & $0.141^{*}$ \\
\hline & $(0.069)$ & $(0.046)$ & $(0.054)$ & $(0.029)$ & $(0.013)$ & $(0.027)$ \\
\hline Non-farm neg & $-0.195^{*}$ & $-0.208^{*}$ & $-0.107^{*}$ & $-0.063^{*}$ & $-0.085^{*}$ & $-0.059^{*}$ \\
\hline & $(0.050)$ & $(0.033)$ & $(0.032)$ & $(0.026)$ & $(0.009)$ & $(0.018)$ \\
\hline$D_{M o}$ & $0.126^{*}$ & $0.044^{* *}$ & $0.149^{*}$ & 0.017 & $-0.015^{* *}$ & $0.049^{*}$ \\
\hline & $(0.032)$ & $(0.021)$ & $(0.022)$ & $(0.014)$ & $(0.008)$ & $(0.018)$ \\
\hline$D_{\text {Tue }}$ & 0.029 & -0.027 & $0.055^{*}$ & -0.004 & -0.005 & $0.033^{* *}$ \\
\hline & $(0.025)$ & $(0.017)$ & $(0.020)$ & $(0.010)$ & $(0.007)$ & $(0.015)$ \\
\hline$D_{W e d}$ & 0.029 & $-0.042^{*}$ & $0.084^{*}$ & 0.013 & -0.006 & $0.050^{*}$ \\
\hline & $(0.025)$ & $(0.017)$ & $(0.020)$ & $(0.012)$ & $(0.007)$ & $(0.016)$ \\
\hline$D_{T h u}$ & -0.033 & $-0.033^{* *}$ & 0.011 & -0.014 & $-0.013^{* *}$ & 0.007 \\
\hline & $(0.024)$ & $(0.017)$ & $(0.020)$ & $(0.010)$ & $(0.007)$ & $(0.015)$ \\
\hline Expiry $_{10,30}$ & $0.134^{* *}$ & - & $0.211^{*}$ & 0.040 & - & $-0.036^{*}$ \\
\hline & $(0.065)$ & - & $(0.014)$ & $(0.031)$ & - & $(0.010)$ \\
\hline Expiry $_{2,5}$ & -0.016 & - & $0.092^{*}$ & - & - & $-0.026^{*}$ \\
\hline & $(0.079)$ & - & $(0.014)$ & - & - & $(0.010)$ \\
\hline$M_{2}$ & - & $0.108^{*}$ & $0.049^{*}$ & - & $-0.071^{*}$ & 0.009 \\
\hline & - & $(0.013)$ & $(0.014)$ & - & $(0.007)$ & $(0.010)$ \\
\hline$M_{5}$ & - & -0.014 & 0.030 & - & $-0.030^{*}$ & -0.048 \\
\hline & - & $(0.013)$ & $(0.059)$ & - & $(0.006)$ & $(0.033)$ \\
\hline$M_{10}$ & - & 0.002 & 0.023 & - & -0.008 & 0.033 \\
\hline & - & $(0.013)$ & $(0.050)$ & - & $(0.006)$ & $(0.038)$ \\
\hline
\end{tabular}

Note: $* * *, * *$ and ${ }^{*}$ indicate statistical significance at $10 \%, 5 \%$ and $1 \%$. (Standard errors). Exp $p_{2,5}$, is excluded from the conflicting maturity pairs due to no conflicting days on expiry dates for these maturities. Surp, Non - farm pos and Non - farm neg represent standardized surprises from: news releases other than non-farm payrolls, positive non-farm payrolls and negative non-farm payrolls. 


\section{List of NCER Working Papers}

No. 55 (Download full text)

Martin G. Kocher, Marc V. Lenz and Matthias Sutter

Psychological pressure in competitive environments: Evidence from a randomized natural experiment: Comment

No. 54 (Download full text)

Adam Clements and Annastiina Silvennoinen

Estimation of a volatility model and portfolio allocation

No. 53 (Download full text)

Luis Catão and Adrian Pagan

The Credit Channel and Monetary Transmission in Brazil and Chile: A Structured VAR

Approach

No. 52 (Download full text)

Vlad Pavlov and Stan Hurn

Testing the Profitability of Technical Analysis as a Portfolio Selection Strategy

No. 51 (Download full text)

Sue Bridgewater, Lawrence M. Kahn and Amanda H. Goodall

Substitution Between Managers and Subordinates: Evidence from British Football

No. 50 (Download full text)

Martin Fukac and Adrian Pagan

Structural Macro-Econometric Modelling in a Policy Environment

No. 49 (Download full text)

Tim M Christensen, Stan Hurn and Adrian Pagan

Detecting Common Dynamics in Transitory Components

No. 48 (Download full text)

Egon Franck, Erwin Verbeek and Stephan Nüesch

Inter-market Arbitrage in Sports Betting

No. 47 (Download full text)

Raul Caruso

Relational Good at Work! Crime and Sport Participation in Italy. Evidence from Panel Data Regional Analysis over the Period 1997-2003.

No. 46 (Download full text) (Accepted)

Peter Dawson and Stephen Dobson

The Influence of Social Pressure and Nationality on Individual Decisions: Evidence from the Behaviour of Referees

No. 45 (Download full text)

Ralf Becker, Adam Clements and Christopher Coleman-Fenn

Forecast performance of implied volatility and the impact of the volatility risk premium 
No. 44 (Download full text)

Adam Clements and Annastiina Silvennoinen

On the economic benefit of utility based estimation of a volatility model

No. 43 (Download full text)

Adam Clements and Ralf Becker

A nonparametric approach to forecasting realized volatility

No. 42 (Download full text)

Uwe Dulleck, Rudolf Kerschbamer and Matthias Sutter

The Economics of Credence Goods: On the Role of Liability, Verifiability, Reputation and Competition

No. 41 (Download full text)

Adam Clements, Mark Doolan, Stan Hurn and Ralf Becker

On the efficacy of techniques for evaluating multivariate volatility forecasts

No. 40 (Download full text)

Lawrence M. Kahn

The Economics of Discrimination: Evidence from Basketball

No. 39 (Download full text)

Don Harding and Adrian Pagan

An Econometric Analysis of Some Models for Constructed Binary Time Series

No. 38 (Download full text)

Richard Dennis

Timeless Perspective Policymaking: When is Discretion Superior?

No. 37 (Download full text)

Paul Frijters, Amy Y.C. Liu and Xin Meng

Are optimistic expectations keeping the Chinese happy?

No. 36 (Download full text)

Benno Torgler, Markus Schaffner, Bruno S. Frey, Sascha L. Schmidt and Uwe Dulleck

Inequality Aversion and Performance in and on the Field

No. 35 (Download full text)

T M Christensen, A. S. Hurn and K A Lindsay

Discrete time-series models when counts are unobservable

No. 34 (Download full text)

Adam Clements, A S Hurn and K A Lindsay

Developing analytical distributions for temperature indices for the purposes of pricing temperature-based weather derivatives

No. 33 (Download full text)

Adam Clements, A S Hurn and K A Lindsay

Estimating the Payoffs of Temperature-based Weather Derivatives 
No. 32 (Download full text)

T M Christensen, A S Hurn and K A Lindsay

The Devil is in the Detail: Hints for Practical Optimisation

No. 31 (Download full text)

Uwe Dulleck, Franz Hackl, Bernhard Weiss and Rudolf Winter-Ebmer

Buying Online: Sequential Decision Making by Shopbot Visitors

No. 30 (Download full text)

Richard Dennis

Model Uncertainty and Monetary Policy

No. 29 (Download full text)

Richard Dennis

The Frequency of Price Adjustment and New Keynesian Business Cycle Dynamics

No. 28 (Download full text)

Paul Frijters and Aydogan Ulker

Robustness in Health Research: Do differences in health measures, techniques, and time frame matter?

No. 27 (Download full text)

Paul Frijters, David W. Johnston, Manisha Shah and Michael A. Shields

Early Child Development and Maternal Labor Force Participation: Using Handedness as an Instrument

No. 26 (Download full text)

Paul Frijters and Tony Beatton

The mystery of the U-shaped relationship between happiness and age.

No. 25 (Download full text)

T M Christensen, A S Hurn and K A Lindsay

It never rains but it pours: Modelling the persistence of spikes in electricity prices

No. 24 (Download full text)

Ralf Becker, Adam Clements and Andrew McClelland

The Jump component of S\&P 500 volatility and the VIX index

No. 23 (Download full text)

A. S. Hurn and V.Pavlov

Momentum in Australian Stock Returns: An Update

No. 22 (Download full text)

Mardi Dungey, George Milunovich and Susan Thorp

Unobservable Shocks as Carriers of Contagion: A Dynamic Analysis Using Identified

Structural GARCH

No. 21 (Download full text) (forthcoming)

Mardi Dungey and Adrian Pagan

Extending an SVAR Model of the Australian Economy 
No. 20 (Download full text)

Benno Torgler, Nemanja Antic and Uwe Dulleck

Mirror, Mirror on the Wall, who is the Happiest of Them All?

No. 19 (Download full text)

Justina AV Fischer and Benno Torgler

Social Capital And Relative Income Concerns: Evidence From 26 Countries

No. 18 (Download full text)

Ralf Becker and Adam Clements

Forecasting stock market volatility conditional on macroeconomic conditions.

No. 17 (Download full text)

Ralf Becker and Adam Clements

Are combination forecasts of S\&P $\mathbf{5 0 0}$ volatility statistically superior?

No. 16 (Download full text)

Uwe Dulleck and Neil Foster

Imported Equipment, Human Capital and Economic Growth in Developing Countries

No. 15 (Download full text)

Ralf Becker, Adam Clements and James Curchin

Does implied volatility reflect a wider information set than econometric forecasts?

No. 14 (Download full text)

Renee Fry and Adrian Pagan

Some Issues in Using Sign Restrictions for Identifying Structural VARs

No. 13 (Download full text)

Adrian Pagan

Weak Instruments: A Guide to the Literature

No. 12 (Download full text)

Ronald G. Cummings, Jorge Martinez-Vazquez, Michael McKee and Benno Torgler

Effects of Tax Morale on Tax Compliance: Experimental and Survey Evidence

No. 11 (Download full text)

Benno Torgler, Sascha L. Schmidt and Bruno S. Frey

The Power of Positional Concerns: A Panel Analysis

No. 10 (Download full text)

Ralf Becker, Stan Hurn and Vlad Pavlov

Modelling Spikes in Electricity Prices

No. 9 (Download full text)

A. Hurn, J. Jeisman and K. Lindsay

Teaching an Old Dog New Tricks: Improved Estimation of the Parameters of Stochastic Differential Equations by Numerical Solution of the Fokker-Planck Equation 
No. 8 (Download full text)

Stan Hurn and Ralf Becker

Testing for nonlinearity in mean in the presence of heteroskedasticity.

No. 7 (Download full text) (published)

Adrian Pagan and Hashem Pesaran

On Econometric Analysis of Structural Systems with Permanent and Transitory Shocks and Exogenous Variables.

No. 6 (Download full text) (published)

Martin Fukac and Adrian Pagan

Limited Information Estimation and Evaluation of DSGE Models.

No. 5 (Download full text)

Andrew E. Clark, Paul Frijters and Michael A. Shields

Income and Happiness: Evidence, Explanations and Economic Implications.

No. 4 (Download full text)

Louis J. Maccini and Adrian Pagan

Inventories, Fluctuations and Business Cycles.

No. 3 (Download full text)

Adam Clements, Stan Hurn and Scott White

Estimating Stochastic Volatility Models Using a Discrete Non-linear Filter.

No. 2 (Download full text)

Stan Hurn, J.Jeisman and K.A. Lindsay

Seeing the Wood for the Trees: A Critical Evaluation of Methods to Estimate the Parameters of Stochastic Differential Equations.

No. 1 (Download full text)

Adrian Pagan and Don Harding

The Econometric Analysis of Constructed Binary Time Series. 